Received: 20 December 2016 Accepted: 15 June 2017 Published online: 24 July 2017
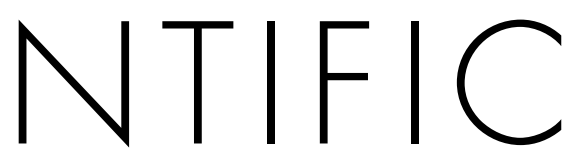
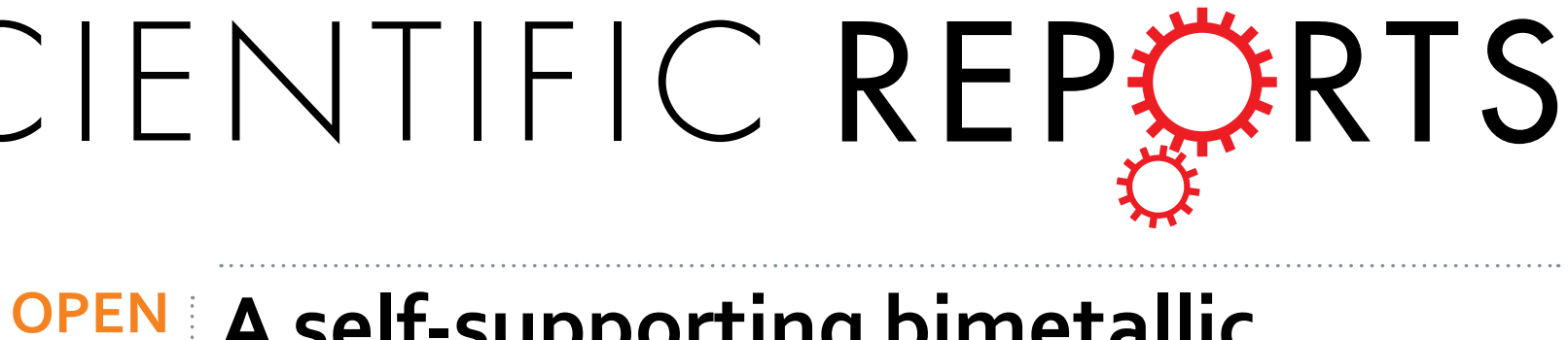

\title{
A self-supporting bimetallic
} Au@Pt core-shell nanoparticle electrocatalyst for the synergistic enhancement of methanol oxidation

\author{
Changhui Tan ${ }^{1,2,3}$, Yinghui Sun ${ }^{4}$, Jianzhong Zheng ${ }^{1}$, Dan Wang ${ }^{1}$, Ziyang Li ${ }^{1}$, Huajie Zeng ${ }^{1}$, Jun \\ Guo ${ }^{5}$, Liqiang Jing $\mathbb{D}^{3} \&$ Lin Jiang ${ }^{1}$
}

The morphology of $\mathrm{Pt}-\mathrm{Au}$ bimetal nanostructures plays an important role in enhancing the catalytic capability, catalytic stability and utilization efficiency of the platinum. We designed and successfully prepared Au@Pt nanoparticles (NPs) through an economical, surfactant-free and efficient method of seed-mediated growth. The Au@Pt NPs displayed electrochemical performances superior to those of commercial $\mathrm{Pt} / \mathrm{C}$ catalysts because their agglomeration was prevented and exhibited better long-term stability with respect to methanol oxidation in acidic media by efficiently removing intermediates. Among the obtained Au@Pt NPs, $\mathrm{Au}_{90} @ \mathrm{Pt}_{10} \mathrm{NPs}$ exhibited the most significantly enhanced catalytic performance for the methanol oxidation reaction (MOR). Their mass and electrochemically active surface area (ECSA)-normalized current densities are approximately 3.9 and 4.6 times higher than those of commercial Pt/C catalysts, respectively. The oxidation current densities of the $\mathrm{Au}_{90} @ \mathrm{Pt}_{10}$ NPs are approximately 1.8 times higher than those of commercial Pt/C catalysts after $4000 \mathrm{~s}$ of continuous measurement because the small Pt NPs grown on the surface of the $\mathrm{Au}_{90} @ \mathrm{Pt}_{10} \mathrm{NPs}_{\mathrm{s}}$ were effectively stabilized by the Au metal support. This approach may be a facile method for the synthesis of self-supported bimetallic nanostructures, which is of great significance for the development of high performance electrocatalysts and sensors.

In the face of the oil and other fossil fuel crises, the development of clean and sustainable energy sources has become an increasingly important concern. Direct methanol fuel cells (DMFCs) are the desired power source for electronic devices because of the high energy density of methanol and its biological renewability, high energy conversion efficiency, low cost and very low environmental pollution ${ }^{1-4}$. Platinum $(\mathrm{Pt})$ is generally considered the most efficient and common catalyst for both anodes and cathodes for DMFCs ${ }^{5-16}$. However, first, the relative scarcity and high cost of Pt hinder the large-scale manufacture and development of DMFCs ${ }^{17-19}$. Second, the stability and activity of catalysts are major challenges for widespread applications of DMFCs. Other metals (e.g., $\mathrm{Au}, \mathrm{Ag}, \mathrm{Pd}, \mathrm{Ni}, \mathrm{Fe}, \mathrm{Cu}$ ) have been introduced into Pt to form Pt-based nanostructures, which not only minimize the usage of Pt but also improve the overall electrocatalytic performance ${ }^{20-28}$. Therefore, the design and synthesis

${ }^{1}$ Institute of Functional Nano \& Soft Materials Laboratory (FUNSOM), Jiangsu Key Laboratory for CarbonBased Functional Materials \& Devices, Soochow University, Suzhou, 215123, China. ${ }^{2}$ College of Chemistry and Environment, Fujian Province Key Laboratory of Morden Analytical Science and Separation Technology, Minnan Normal University, Zhangzhou, 363000, P. R. China. ${ }^{3}$ Key Laboratory of Functional Inorganic Materials Chemistry (Heilongjiang University), Ministry of Education, School of Chemistry and Materials Science, Harbin, 150080, P. R. China. ${ }^{4}$ Soochow Institute for Energy and Materials InnovationS, College of Physics, Optoelectronics and Energy \& Collaborative Innovation Center of Suzhou Nano Science and Technology, Soochow University, Suzhou, 215006, China. ${ }^{5}$ Testing and Analysis Center, Soochow University, Suzhou, 215123, China. Changhui Tan and Yinghui Sun contributed equally to this work. Correspondence and requests for materials should be addressed to L.J. (email: ljiang@suda.edu.cn) 
of Pt-based nanostructures with enhanced catalytic capability and utilization efficiency of Pt is an ongoing goal of chemists.

Bimetallic systems with synergistic effects that are tunable through variations of composition and structure have many potential applications in the methanol oxidation reaction $(\mathrm{MOR})^{29-31}$. To enhance the mass activity of Pt-based catalysts, one of the most typical strategies is to incorporate non- $\mathrm{Pt}(\mathrm{M})$ metals into the Pt nanoparticles (NPs) by alloying technology or by using core-shell composite bimetallic nanostructures ${ }^{32-40}$. In core-shell bimetallic nanostructures, the M metal is the core of the NPs, and Pt metal is located on the surface the M core. Thus, because of the interaction between $\mathrm{Pt}$ and $\mathrm{M}$, not only is the catalytic activity greatly enhanced but also the usage of Pt metal is notably decreased ${ }^{31,41}$. To date, core-shell nanostructures with enhanced performances as catalysts for the methanol oxidation reaction (MOR) have been observed ${ }^{42-53}$. Gold ( $\mathrm{Au}$ ) is a unique metal since it is inert in the bulk state but has high catalytic activity for many reactions at the nanoscale ${ }^{54-57}$. The special properties of $\mathrm{Au}$ at the nanoscale have also been found to grant unparalleled electrocatalytic activity for CO oxidation $^{58-60}$. Consequently, bimetallic $\mathrm{Pt}-\mathrm{Au}$ nanocatalysts are expected to exhibit synergistic catalytic effects toward the MOR. First, Pt in the shell of Au-Pt core-shell nanostructures grows on the surface of Au and shares the same crystalline directions as the Au support ${ }^{61,62}$. Second, Au is inert in acid electrolytes, demonstrating high chemical stability and durability as a catalyst component ${ }^{63}$. Third, the synergistic effect from the Au and Pt interaction alters the structure of the Pt electronic bands by changing the surface adsorption force ${ }^{31,64-66}$, which contributes to a significant enhancement of both electrocatalytic activity and stability that could grant improved CO tolerance to Pt catalysts in the MOR. Various approaches have been developed to synthesize bimetallic Au-Pt core-shell nanostructures, including solvothermal, electrodeposition or template methods. However, these preparation methods usually require high temperatures, surfactants, electrical energy and/or sacrificial templates ${ }^{42,44-47,49,50}$, which create complicated, power-wasting and time-consuming processes. Moreover, the surfactant-stabilizing nanostructures interfere with the catalytic performance of $\mathrm{Pt}$ in the $\mathrm{MOR}^{67}$.

Herein, we demonstrate a facile and surfactant-free approach for the synthesis of spiny Au@Pt core-shell nanoparticles. The reason for choosing spiny Au NPs as cores for Pt growth is that spiny Au NPs have a large specific surface area because of the high density of spines on the Au NP surface, and the small Pt NPs can be uniformly loaded on the naked surface of spiny Au NPs without surfactant capping. Thus, both electrocatalytic stability and activity are greatly enhanced in methanol oxidation in acidic conditions. With the optimized Pt amount loading on the spiny Au NPs, the $\mathrm{Au}_{90} @ \mathrm{Pt}_{10} \mathrm{NPs}$ exhibited enhanced catalytic performance, with their mass and electrochemically active surface area (ECSA)-normalized current densities being approximately 3.9 and 4.6 times higher than those of commercial Pt/C catalysts, respectively. Spiny Au NPs play an important role in decreasing precious Pt content and increasing stability and activity during methanol oxidation and signify the importance of supporting matrices in Pt-based catalysts. We expect that this method will serve as a facile and effective approach to fabricate bimetallic nanostructures for further applications in DMFCs with high efficiency.

\section{Results}

Morphological Control of the self-supporting Au@Pt NPs. The preparation procedure of the self-supporting Au@Pt NPs is shown in Fig. 1A. Spiny Au NPs were prepared and used as seeds to synthesize $\mathrm{Au} @ \mathrm{Pt}$ NPs, which is a process of chemical growth and an element-replacement reaction. The synthesized spiny $\mathrm{Au}$ NPs were dispersed into an aqueous solution containing chloroplatinic acid. According to the literature, it is much easier and faster to reduce $\mathrm{Pt}(\mathrm{II})$ ions than $\mathrm{Pt}(\mathrm{IV})$ ions ${ }^{68,69}$. Therefore, the $\mathrm{Pt}(\mathrm{IV})$ ion was chosen in this study to obtain a slow reduction speed. Ascorbic acid was used as a weak reductant to reduce Pt(IV) ion ${ }^{70}$. In this process, the spiny Au NPs provided a nucleation center, and the Pt atoms were uniformly and slowly reduced on the surface of the spiny Au NPs. The reduction of the Pt(IV) ions more preferentially occurred on the surface of the spiny Au NPs than in the solution ${ }^{61}$. As the reaction proceeded, more Pt ions were reduced into atoms by L-ascorbic acid and grew into small Pt NPs. These Pt NPs were uniformly loaded on the surface and formed a strong connection with the spiny Au NPs. With the chemical growth of these small Pt NPs, they connected to each other to form a shell on the surface of the spiny Au NPs as the amount of Pt increased. The amount of Pt can be regulated by adding specific volumes of Pt precursors in the synthesis. Au@Pt NPs with different Pt ratios $\left(\mathrm{Au}_{99} @ \mathrm{Pt}_{1}, \mathrm{Au}_{95} @ \mathrm{Pt}_{5}, \mathrm{Au}_{90} @ \mathrm{Pt}_{10}, \mathrm{Au}_{85} @ \mathrm{Pt}_{15}\right)$ were obtained by changing the injected amount of chloroplatinic acid $\left(\mathrm{H}_{2} \mathrm{PtCl}_{6}\right)$ and were determined by inductively coupled plasma atomic emission spectroscopy (ICP-AES) (see Supplementary Table S1).

The micromorphology of the Au@Pt NPs was evaluated by scanning electron microscopy (SEM) as shown in Fig. 1B-E. The spiny Au NPs are evenly dispersed and have little agglomeration, with uniform shapes and an average diameter of approximately $80 \mathrm{~nm}$, which provides good conditions for the direct growth of the Pt NPs (see Supplementary Figure S1). After being decorated with small Pt NPs, the Au@Pt NPs retained a morphology similar to that of the spiny Au NPs. With a lower coated quantity of platinum, the morphology of the $\mathrm{Au}_{99} @ \mathrm{Pt}_{1} \mathrm{NPs}$ Pt appears almost the same as that of the spiny Au NPs (Fig. 1B), where it is difficult to observe any clear small Pt NPs on the surface of the spiny Au NPs. As shown in Fig. 1C-E, with the increase in the amount of platinum from the $A_{95} @ \mathrm{Pt}_{5} \mathrm{NPs}$ to the $\mathrm{Au}_{90} @ \mathrm{Pt}_{10} \mathrm{NPs}$, Pt NPs were clearly observed to be distributed on the surfaces of the spiny Au NPs. If the coated quantity of platinum was excessive, so many Pt NPs were coated onto the surfaces of the spiny Au NPs that the Pt NPs were overgrown on the surface, creating the appearance that the spines were getting shorter, as shown in Fig. 1E.

Transmission electron microscopy (TEM) was performed to further analyze the structure and components of the Au@Pt NPs. As shown in Fig. 2, Pt nanoparticles were uniformly distributed on the surfaces of the spiny Au NPs. Figure 2A shows that $\mathrm{Au}_{99} @ \mathrm{Pt}_{1} \mathrm{NPs}$, prepared at a low concentration of $\mathrm{H}_{2} \mathrm{PtCl}_{6}$ in solution, had only a small quantity of Pt NPs dispersed on the tips of the spiny Au NPs. When the concentration of $\mathrm{H}_{2} \mathrm{PtCl}_{6}$ was increased, the increase in Pt NPs on the surfaces and tips of the spiny Au NPs can clearly be observed in Fig. 2B and C. However, in the $\mathrm{Au}_{85} @ \mathrm{Pt}_{15} \mathrm{NPs}$, the surfaces and tips of the spiny Au NPs were completely coated with platinum 
(A)
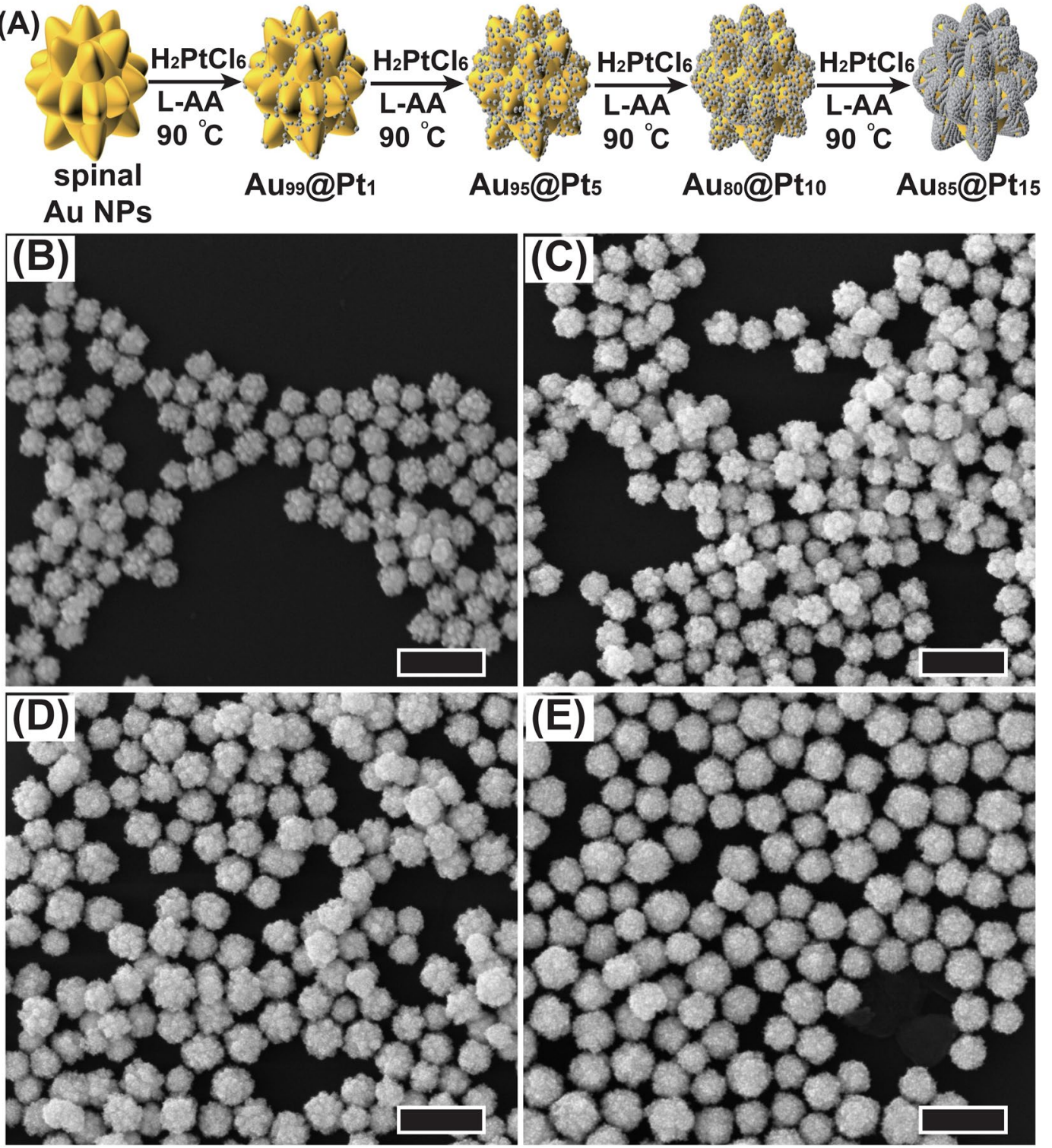

Figure 1. (A) Reaction scheme showing the morphological and structural changes involved in the fabrication of Au@Pt NPs with different Pt ratios. SEM images of Au@Pt NPs with different Pt source amount-modulated

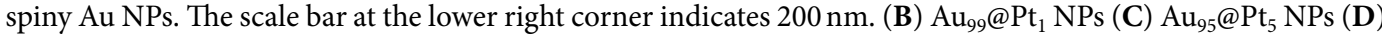
$\mathrm{Au}_{90} @ \mathrm{Pt}_{10} \mathrm{NPs}(\mathbf{E}) \mathrm{Au}_{85} @ \mathrm{Pt}_{15} \mathrm{NPs}$.

nanoparticles, forming a continuous core-shell structure as illustrated in Fig. 2D, which led to nanospheres from the spiny NPs. This result indicated that the concentration of $\mathrm{H}_{2} \mathrm{PtCl}_{6}$ plays an important role in the formation of Pt nanoparticles and that the morphology of the Au@Pt NPs could be tuned by varying the concentration of $\mathrm{H}_{2} \mathrm{PtCl}_{6}$.

The distributions of the metallic elements in the Au@Pt NPs were important to the catalytic ability; they were analyzed by means of high-angle annular dark-field scanning transmission electron microscopy (HAADF-STEM) (Fig. 2E). The merged mapping patterns provided clear evidence for the elemental distribution of $\mathrm{Au}$ and $\mathrm{Pt}$ in the $\mathrm{Au}_{90} @ \mathrm{Pt}_{10} \mathrm{NPs}$, which further indicated the core-shell structure of the $\mathrm{Au}_{90} @ \mathrm{Pt}_{10} \mathrm{NPs}_{\text {. Accordingly, elemental }}$ mapping of $\mathrm{Au}$ (yellow color) demonstrated that $\mathrm{Au}$ is distributed in the interior; $\mathrm{Pt}$ (red color) is decorated on the surface of the spiny Au NPs, and Pt seemed to be homogenously distributed over the entire surface of the Au core at this concentration.

The composition of the $\mathrm{Au}_{90} @ \mathrm{Pt}_{10} \mathrm{NPs}$ was further investigated by X-ray diffraction (XRD), shown in Fig. 3A. The diffraction peaks of the $\mathrm{Au}_{90} @ \mathrm{Pt}_{10}$ NPs can be categorized into two sets. The peaks at two theta values of $38^{\circ}, 44^{\circ}, 64^{\circ}$ and $77^{\circ}$ can be indexed to the (111), (200), (220) and (311) crystal planes of face-centered cubic Au (JCPDS card No. 4-784), respectively, which are similar to the diffraction peaks of the spiny Au NPs. The other set of peaks, at two theta values of $39^{\circ}$ and $46^{\circ}$, can be ascribed to the (111) and (200) crystal planes of face-centered cubic Pt (JCPDS card No. 4-802). The crystal structures of the spiny Au NPs and $\mathrm{Au}_{90} @ \mathrm{Pt}_{10} \mathrm{NPs}_{\text {were further }}$ 

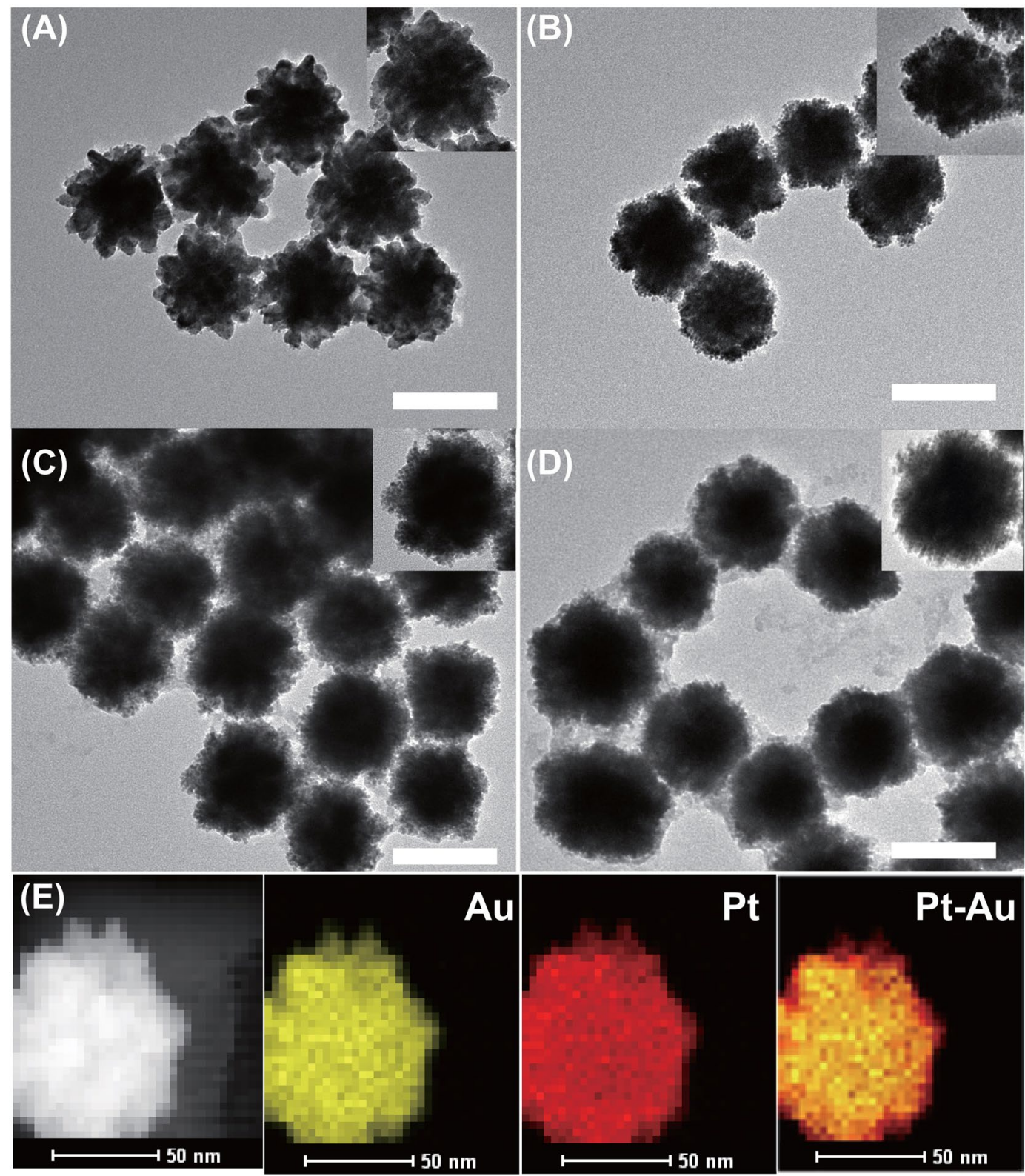

Figure 2. TEM images of different Pt source amount-modulated spiny Au NPs. The insets are the singlenanoparticle views of the four types of Au@Pt NPs. (A) Au $A_{99} @ \mathrm{Pt}_{1} \mathrm{NPs}(\mathbf{B}) \mathrm{Au}_{95} @ \mathrm{Pt}_{5} \mathrm{NPs}_{\mathbf{C}}(\mathbf{C}) \mathrm{Au}_{90} @ \mathrm{Pt}_{10} \mathrm{NPs}$ (D) $\mathrm{Au}_{85} @ \mathrm{Pt}_{15}$ NPs. Scale bar: $100 \mathrm{~nm}$. (E) HAADF-STEM image and elemental mappings of $\mathrm{Au}_{90} @ \mathrm{Pt}_{10} \mathrm{NPs}$

characterized by means of high-resolution TEM (HRTEM). The lattice spacings of the spiny Au and Pt NPs (see Supplementary Figure S2) are 0.235 and $0.226 \mathrm{~nm}$, which match well with the d-spacings of the Au (111) and Pt (111) planes $(0.235 \mathrm{~nm}$ for $\mathrm{Au}, 0.226 \mathrm{~nm}$ for Pt), respectively. These results indicate that Au and Pt nanoparticles exist individually in the $\mathrm{Au}_{90} @ \mathrm{Pt}_{10} \mathrm{NPs}$.

To investigate the interaction of $\mathrm{Au}$ and $\mathrm{Pt}$ and the surface oxidation state, typical X-ray photo electron spectroscopy (XPS) was employed, and the spectra of the $\mathrm{Au}_{90} @ \mathrm{Pt}_{10} \mathrm{NPs}$ are shown in Fig. 3. Figure 3B presents the $\mathrm{Au} 4 \mathrm{f}$ core level spectrum for the $\mathrm{Au}_{90} @ \mathrm{Pt}_{10} \mathrm{NPs}$, in which the peaks at 83.6 and $87.2 \mathrm{eV}$ can be attributed to Au $4 \mathrm{f}_{7 / 2}$ and $\mathrm{Au} 4 \mathrm{f}_{5 / 2}$ of $\mathrm{Au}^{0}$. In the Pt $4 \mathrm{f}$ core level spectrum of the $\mathrm{Au}_{90} @ \mathrm{Pt}_{10}$ NPs (Fig. 3C), two peaks at 71.1 and $74.40 \mathrm{eV}$ can be assigned to $\mathrm{Pt} 4 \mathrm{f}_{7 / 2}$ and $\mathrm{Pt} 4 \mathrm{f}_{5 / 2}$ of $\mathrm{Pt}^{0}$. Additionally, the peaks at 71.9 and $75.2 \mathrm{eV}$ correspond to $\mathrm{Pt}^{2+}$ species ${ }^{71}$. According to the high (or highest) $\mathrm{Pt}^{0} / \mathrm{Pt}^{2+}$ intensity ratio, it can be inferred that the $\mathrm{Pt}^{0}$ species was dominant. Compared to the standard data of pure atomic $\mathrm{Au} 4 \mathrm{f}(84.0$ and $87.7 \mathrm{eV})$, and Pt $4 \mathrm{f}(70.9 \text { and } 74.2 \mathrm{eV})^{36}$, ${ }^{61}$, the binding energies of $\mathrm{Au} 4 \mathrm{f}$ were shifted to lower values, and those of $\mathrm{Pt} 4 \mathrm{f}$ were shifted to higher values. The decrease in the binding energies of $\mathrm{Au} 4 \mathrm{f}$ and the increase in those of $\mathrm{Pt} 4 \mathrm{f}$ suggest that $\mathrm{Au}$ and $\mathrm{Pt}$ in the bimetallic $\mathrm{Au}_{90} @ \mathrm{Pt}_{10} \mathrm{NPs}$ could possess a charge transfer phenomenon. This may contribute to a potential increase in the stability of the Au@Pt NP electrocatalyst. 

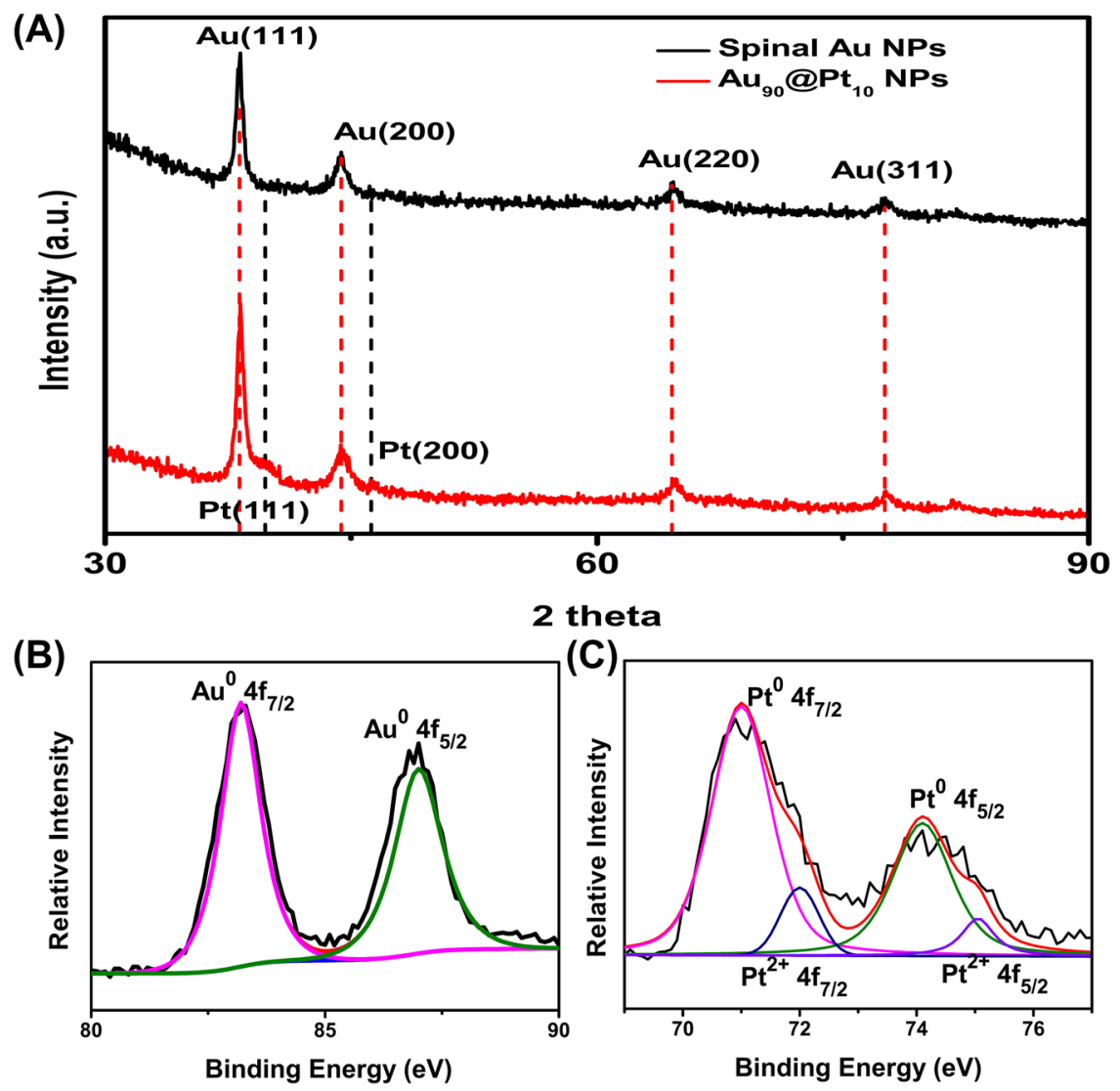

Figure 3. (A) XRD pattern of the $\mathrm{Au}_{90} @ \mathrm{Pt}_{10} \mathrm{NPs}$. (B) Au $4 \mathrm{f}$ and (C) Pt $4 \mathrm{fXPS}$ spectra of the $\mathrm{Au}_{90} @ \mathrm{Pt}_{10} \mathrm{NPs}$

Electrocatalytic Performances of self-supporting Au@Pt NPs toward the MOR. Spiny Au Nps without Pt do not present any electrochemical activity in sulfuric acid and with the addition of ethanol (see Supplementary Figure S3). The electrocatalytic performances of the as-prepared self-supporting Au@Pt NPs with different Pt contents were studied by cyclic voltammetry $(\mathrm{CV})$ at room temperature in nitrogen-purged solutions at a sweep rate of $50 \mathrm{mV} / \mathrm{s}$. The catalytic properties of commercial $20 \% \mathrm{Pt} / \mathrm{C}$ were also tested for comparison. Figure 4A shows that the CV curves of the five catalysts exhibit typical hydrogen adsorption/desorption peaks at potentials between -0.2 and $0.15 \mathrm{~V}$ and oxygen regions in the range of $0.6-1.0 \mathrm{~V}$. The electrochemically active surface area (ECSA) was calculated by measuring the area of the desorption region between -0.2 and $0.15 \mathrm{~V}$ after double-layer correction. The ECSAs of the $A_{99} @ \mathrm{Pt}_{1} \mathrm{NPs}, \mathrm{Au}_{95} @ \mathrm{Pt}_{5} \mathrm{NPs}, \mathrm{Au}_{90} @ \mathrm{Pt}_{10} \mathrm{NPs}$, and $\mathrm{Au}_{85} @ \mathrm{Pt}_{15} \mathrm{NPs}$ are 110.12, 65.11, 55.02 and $42.63 \mathrm{~m}^{2} / \mathrm{g}_{\mathrm{Pt}}$, respectively. Among the as-synthesized Au@Pt NPs, the ECSAs of the $\mathrm{Au}_{95} @ \mathrm{Pt}_{5} \mathrm{NPs}, \mathrm{Au}_{90} @ \mathrm{Pt}_{10} \mathrm{NPs}$, and $\mathrm{Au}_{85} @ \mathrm{Pt}_{15} \mathrm{NPs}$ are lower than that of commercial Pt/C $\left(71.19 \mathrm{~m}^{2} / \mathrm{g}_{\mathrm{Pt}}\right)$. Under the self-supporting situation, for $\mathrm{Au}_{99} @ \mathrm{Pt}_{1} \mathrm{NPs}$, a small quantity of small Pt NPs was distributed on the surface of the spiny Au NPs. Therefore, extensive agglomeration can be inhibited. In the $A_{u_{95}} @ \mathrm{Pt}_{5} \mathrm{NPs}_{\mathrm{A}} \mathrm{Au}_{90} @ \mathrm{Pt}_{10} \mathrm{NPs}$, and $\mathrm{Au}_{85} @ \mathrm{Pt}_{15} \mathrm{NPs}$, small Pt NPs were overgrown on the surface of the spiny Au NPs, and the platinum layer thickened with the increase in $\mathrm{H}_{2} \mathrm{PtCl}_{6}$ concentrations, so the ECSA gradually decreased. This result is consistent with the SEM and TEM observations.

The electrocatalytic property of the Au@Pt NPs for the MOR was examined and compared with that of commercial Pt/C catalysts in a nitrogen-purged $0.5 \mathrm{M} \mathrm{H}_{2} \mathrm{SO}_{4}+0.5 \mathrm{M}$ methanol solution with a scan rate of $50 \mathrm{mV} / \mathrm{s}$. Figures 4B,C display typical CV curves of the methanol oxidation on the Au@Pt NPs and commercial Pt/C catalysts, showing them to differ only slightly in shape, indicating a similar reaction pathway ${ }^{72}$. In the forward sweep, the anodic peak is observed at approximately $0.70 \mathrm{~V}$, which could belong to the characteristic methanol oxidation on the electrode surface. An oxidation peak at approximately $0.45 \mathrm{~V}$ in the reverse scan is probably associated with the removal of the residual carbon species formed in the forward scan. Slight shifts were found in the mass activity CVs and specific activity CVs (Fig. 4B,C). During the forward scan, a slight positive shift compared to $\mathrm{Pt} / \mathrm{C}$ occurred when the Pt loading increased to $10 \%$, and a slight negative shift occurred when the loading reached 15\%, which is associated with the loading amount of Pt on the spiny Au NPs and direct methanol oxida$\operatorname{tion}^{73,74}$. The slight positive shift in the reverse scan was caused by the decrease in Au oxidation, which is higher than that of Pt oxides ${ }^{75}$. Histograms of the mass activities and specific activities for the five catalysts at the peak current for the MOR were calculated and are shown in Fig. 4D,E, respectively. According to the peak current normalized against the ECSA, the $\mathrm{Au}_{90} @ \mathrm{Pt}_{10} \mathrm{NPs}$ has a specific activity of $0.68 \mathrm{~mA} / \mathrm{cm}^{2}$, which is 4.6 times that of commercial $\mathrm{Pt} / \mathrm{C}$. In a previous report, the specific activities of $\mathrm{Pt}-\mathrm{Au}$ nanoporous leaf and $\mathrm{Pt}-\mathrm{Au}$ nanocrystal for the MOR are 1.8 and 3.4 times that of commercial Pt/C, respectively, less than the 4.6-fold increase in this work $^{61,76}$. 

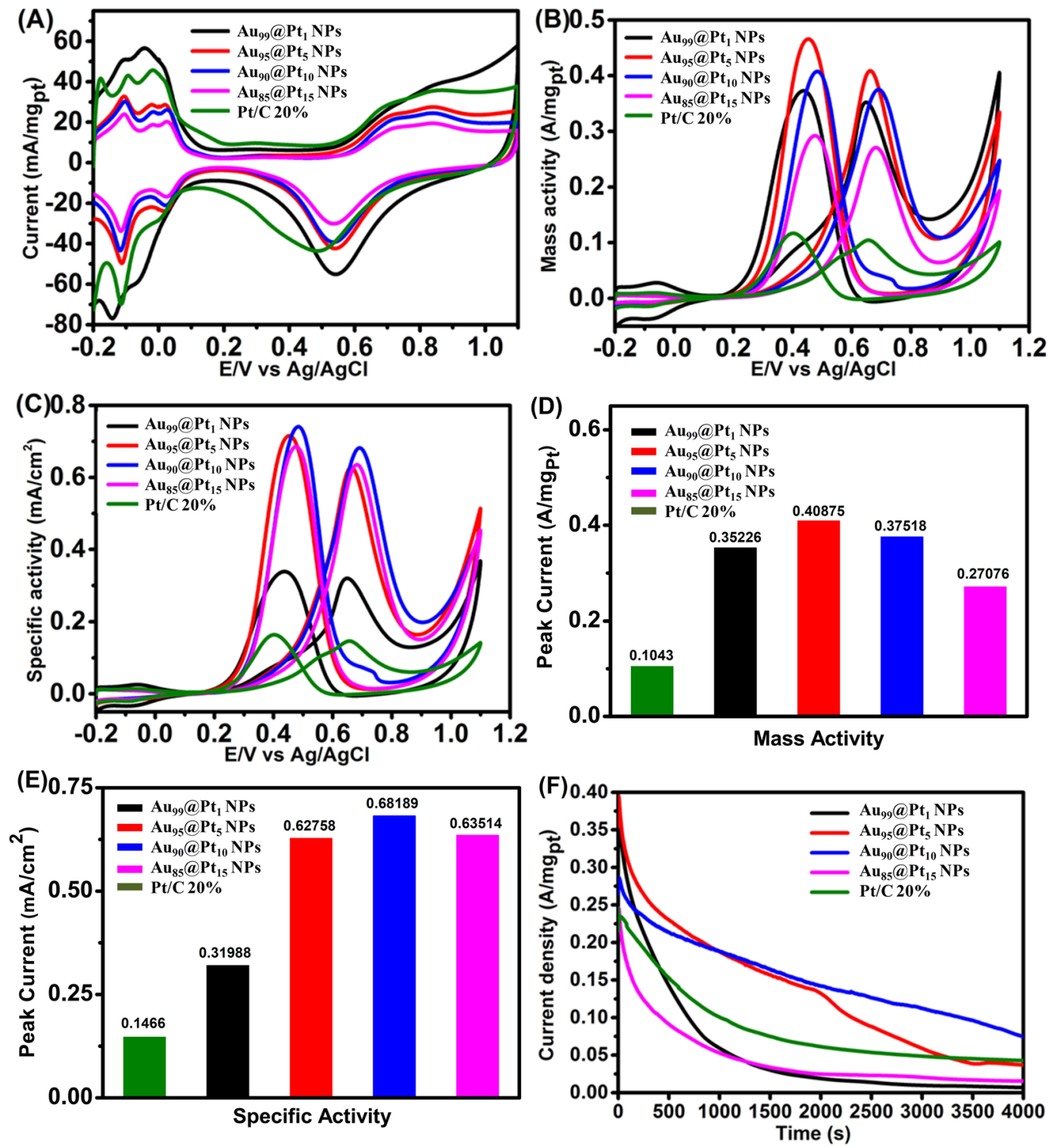

Figure 4. (A) CV curves of the four types of Au@Pt NP catalyst and commercial Pt/C catalyst in $0.5 \mathrm{M} \mathrm{N}_{2^{-}}$ saturated sulfuric acid solution. (B) Mass activity CVs and (C) specific activity CVs of the four types of Au@Pt $\mathrm{NP}$ catalyst and the commercial Pt/C catalyst in $0.5 \mathrm{M} \mathrm{H}_{2} \mathrm{SO}_{4}+0.5 \mathrm{M} \mathrm{CH}_{3} \mathrm{OH}$. Histograms of the peak current of the four types of Au@Pt NP catalyst and the commercial Pt/C catalyst: (D) Mass activity, (E) Specific activity. (F) Chronoamperometric curves of the four types of Au@Pt NP catalyst and the commercial Pt/C catalyst.

The mass activities of the Au@Pt NPs were higher than that of commercial Pt/C toward methanol oxidation, and the $\mathrm{Au}_{95} @ \mathrm{Pt}_{5} \mathrm{NPs}$ showed the best catalytic performance, 3.9 times that of commercial Pt/C. It is reasonable to deduce that the introduction of Au into Pt can increase the catalytic activity of the Pt. In contrast to the carbon support in commercial Pt/C, the improved catalytic activity of Au@Pt NPs can be ascribed to electronic effect modifications. As demonstrated by XPS, the binding energies of Pt in the Au@Pt NPs are up-shifted, which could decrease the CO adsorption energy on Pt and favor C-H cleavage on Pt sites owing to the shift of the d-band center $^{36,77}$. In addition, Au could advance the oxidation of $\mathrm{CO}$ to enhance the tolerance of $\mathrm{CO}$. As a result, Au@ Pt NPs could eliminate the CO intermediates more easily than commercial Pt/C could. On the other hand, unlike with the agglomeration of Pt NPs, the platinum layer on the Au@Pt NPs is thinner, adhering to the surface of the spiny Au NPs, and well dispersed, accordingly resulting in a high mass activity 3.9 times higher than that of commercial $\mathrm{Pt} / \mathrm{C}$, which is higher than previously reported values ${ }^{31,61,78}$.

The catalytic performances of the Au@Pt NPs shows that the amount of Pt on the surface of the spiny Au NPs has an optimal value, which has an important influence on the catalytic properties. As shown in Fig. 4D and E, the catalytic properties of the $\mathrm{Au}_{95} @ \mathrm{Pt}_{5} \mathrm{NPs}$ and $\mathrm{Au}_{90} @ \mathrm{Pt}_{10} \mathrm{NPs}$ were significantly better than those of the $\mathrm{Au}_{99} @$ $\mathrm{Pt}_{1} \mathrm{NPs}$ and $\mathrm{Au}_{85} @ \mathrm{Pt}_{15} \mathrm{NPs}$. This result is similar to those reported in previous literature ${ }^{61}$, where the optimal MOR activity appears when $10 \% \mathrm{Pt}$ is loaded on $\mathrm{Au}$ HNU surfaces. In our $\mathrm{Au}_{85} @ \mathrm{Pt}_{15} \mathrm{NPs}$, all the Au metal is embedded in the center, and only the Pt NPs form the surface. Thus, Au metal is restricted to enhancing the 
catalytic properties, leading to catalytic abilities lower than those of the $\mathrm{Au}_{95} @ \mathrm{Pt}_{5} \mathrm{NPs}$ and $\mathrm{Au}_{90} @ \mathrm{Pt}_{10} \mathrm{NPs}$. As demonstrated by TEM, the Pt NPs in the $\mathrm{Au}_{99} @ \mathrm{Pt}_{1} \mathrm{NPs}$ are rare on the surfaces of the spiny Au NPs. Therefore, the low Pt content on the surface of the $\mathrm{Au}_{99} @ \mathrm{Pt}_{1} \mathrm{NPs}$ would also reduce the catalytic properties for the MOR.

The steady-state catalytic activities of five catalysts were evaluated using chronoamperometry at a constant potential of $0.60 \mathrm{~V}$ for a period of $4000 \mathrm{~s}$, and the resulting $i-t$ curves are shown in Fig. 4F. The polarization currents for all the catalysts decrease rapidly because intermediate species are formed during the MOR process. The methanol oxidation current density of the $\mathrm{Au}_{90} @ \mathrm{Pt}_{10} \mathrm{NPs}$ over a period of $4000 \mathrm{~s}$ is the highest among those of all the catalysts examined. At the end of $4000 \mathrm{~s}$, the $\mathrm{Au}_{90} @ \mathrm{Pt}_{10} \mathrm{NPs}$ display much slower current density decay with time, further revealing a better tolerance toward the CO-like intermediates.

\section{Conclusion}

In summary, an economical, surfactant-free and efficient synthetic route using a seeded-growth method was used to form Au@Pt NPs. The Au@Pt NPs exhibited important improvements in catalytic response in comparison to commercial $\mathrm{Pt} / \mathrm{C}$ catalyst towards methanol oxidation in acidic conditions. The best response for methanol oxidation was achieved from the $\mathrm{Au}_{90} @ \mathrm{Pt}_{10} \mathrm{NPs}$, which was 4.6 times greater than that of commercial Pt/C in terms of per mg Pt activity in acidic media. The as-synthesized catalysts are not only very efficient in reducing the usage of Pt but are also promising candidates for methanol electro-oxidation.

\section{Methods}

Reagents and chemicals. Hydrogen hexachloroplatinate (IV) $\left(\mathrm{H}_{2} \mathrm{PtCl}_{6}, \geq 99.9 \%\right)$ and gold(III) tetrachloride trihydrate $\left(\mathrm{HAuCl}_{4} \cdot 3 \mathrm{H}_{2} \mathrm{O}, \geq 49.0 \%\right)$ were provided by Sigma. Commercial $\mathrm{Pt} / \mathrm{C}(20 \mathrm{wt}$. \%) was provided by Johnson Matthey. L-Ascorbic acid (AA, $\geq 99.7 \%)$ and methanol ( $\geq 99.7 \%)$ were purchased from Sinopharm Chemical Reagent Co. Ltd. All reagents and chemicals were used as received. Ultrapure water $(18.2 \mathrm{M} \Omega \mathrm{cm})$ from a Milli-pore system was used in all experiments.

Characterizations. X-ray photoelectron spectroscopy (XPS) was performed using a PHI 5000 Versa Probe with $\mathrm{Al} \mathrm{K \alpha}$ as the excitation source. Scanning electron microscopy (SEM) images of as-prepared Au@Pt NPs were observed with a Carl Zeiss Supra 55 San electron microscope. Transmission electron microscopy (TEM) and HRTEM characterization were performed with an FEI Tecnai G2 F20 S-Twin electron microscope (200kV). Structural analysis of the Au@Pt NPs was performed in scanning TEM (STEM) mode on an FEI Tecnai G2 F20 electron microscope $(200 \mathrm{kV})$ equipped with an energy dispersive X-ray spectrometer (EDS). The STEM images were captured with a high-angle annular dark-field (HAADF) detector. Powder X-ray diffraction (XRD) was performed on a Rigaku D/max-rA X-ray diffractometer with graphite monochromatized CuK $\alpha$ radiation. The ICP (VISTA-MPX) was used to determine the content of the as-prepared Au@Pt NPs.

Measurement of the electrochemical properties was performed on a CHI-660D electrochemical workstation with a conventional three-electrode system (ChenHua Corp., Shanghai, China). An as-prepared Au@Pt NP-modified carbon glass electrode (GCE, $3 \mathrm{~mm}$ in diameter, $0.071 \mathrm{~cm}^{2}$ ) served as a working electrode. A Pt wire was used as the counter electrode, and an $\mathrm{Ag} / \mathrm{AgCl}$ electrode was used as the reference electrode. A water suspension of the as-prepared Au@Pt NPs $\left(6 \mu \mathrm{L}, 5.872 \times 10^{-11} \mathrm{~mol}\right)$ was dropped onto the cleaned GCE and dried in air at room temperature. After evaporation of the water, $5 \mu \mathrm{L}$ of Nafion solution $(0.05 \mathrm{wt}$. \%, diluted from $5 \mathrm{wt}$. $\%$ Nafion with ethanol) was pipetted onto the catalyst film and dried in air. The blank scans were performed in $0.5 \mathrm{M}$ $\mathrm{H}_{2} \mathrm{SO}_{4}$ purged with nitrogen and cycled from -0.2 to $1.1 \mathrm{~V}$. Methanol oxidation reactions (MORs) were performed in a $\mathrm{N}_{2}$-saturated aqueous solution containing $0.5 \mathrm{M}$ methanol and $0.5 \mathrm{M} \mathrm{H}_{2} \mathrm{SO}_{4}$. All measurements were recorded with a scan rate of $50 \mathrm{mV} \mathrm{s}^{-1}$. Chronoamperometric curves for the MOR were recorded at the potential of $0.60 \mathrm{~V}$ for $4000 \mathrm{~s}$. All the potentials in this study were reported with respect to $\mathrm{Ag} / \mathrm{AgCl}$, and all electrochemical data were obtained at room temperature.

Preparation of the spiny Au NPs. Five hundred microliters of gold seeds ( $40 \mathrm{~nm}$ ) was added to aqueous solutions (approximately $6.5 \mathrm{pH}$ ) adjusted by $6 \mathrm{~mL}$ of sodium citrate solution (5\%). Under mild shaking, $0.3 \mathrm{~mL}$ of $0.01 \mathrm{M} \mathrm{HAuCl}_{4}$ was added into the seeds mixture, shifting the color of the solution from pale pink to cyan, blue and light purple. The resulting spiny Au NPs were collected by centrifugation at $5000 \mathrm{rpm}$ for $7 \mathrm{~min}$, washed by water several times and were dispersed into water for further use.

Preparation of the Au@Pt NPs. In a typical synthesis, a mixture of $30.00 \mathrm{~mL}$ of water and $1.00 \mathrm{~mL}$ of the spiny Au NP solution $(7.34 \mathrm{nM})$ was added to a $50 \mathrm{~mL}$ glass bottle. Then, $1.00 \mathrm{~mL}$ of $0.1 \mathrm{M} \mathrm{L}$-ascorbic acid was added into the above solution with magnetic stirring. After that, the bottle was placed into a water bath at $90^{\circ} \mathrm{C}$. Then, $0.2 \mathrm{~mL}$ of $\mathrm{H}_{2} \mathrm{PtCl}_{6}$ solution $(20.0 \mathrm{mM})$ was added with strong stirring, and the solution was maintained at $90^{\circ} \mathrm{C}$ for $15 \mathrm{~min}$. Finally, the product was collected by centrifugation at $3000 \mathrm{rpm}$ for $7 \mathrm{~min}$ and washed by water several times. The Au@Pt NPs with different Pt ratios $\left(\mathrm{Au}_{99} @ \mathrm{Pt}_{1}, \mathrm{Au}_{95} @ \mathrm{Pt}_{5}, \mathrm{Au}_{90} @ \mathrm{Pt}_{10}, \mathrm{Au}_{85} @ \mathrm{Pt}_{15}\right)$ were synthesized by varying the injected volume of the Pt precursor from 0.1 to $0.4 \mathrm{~mL}$.

\section{References}

1. Chen, C. et al. Highly crystalline multimetallic nanoframes with three-dimensional electrocatalytic surfaces. Science 343, 1339-1343 (2014).

2. Liu, M., Lu, Y. \& Chen, W. PdAg nanorings supported on graphene nanosheets: Highly methanol-tolerant cathode electrocatalyst for alkaline fuel cells. Adv. Funct. Mater. 23, 1289-1296 (2013).

3. Habas, S. E. et al. Shaping binary metal nanocrystals through epitaxial seeded growth. Nat. Mater. 6, 692-697 (2007).

4. Liu, M., Zhang, R. \& Chen, W. Graphene-supported nanoelectrocatalysts for fuel cells: synthesis, properties, and applications. Chem. Rev. 114, 5117-5160 (2014).

5. Zhang, H., Jin, M. \& Xia, Y. Enhancing the catalytic and electrocatalytic properties of Pt-based catalysts by forming bimetallic nanocrystals with Pd. Chem. Soc. Rev. 41, 8035-8049 (2012). 
6. You, S. et al. Enhanced cathodic oxygen reduction and power production of microbial fuel cell based on noble-metal-free electrocatalyst derived from metal-organic frameworks. Adv. Energy Mater. 6, 1501497 (2016).

7. Sun, Y. et al. Ultrasonic-electrodeposition of PtPd alloy nanoparticles on ionic liquid-functionalized graphene paper: towards a flexible and versatile nanohybrid electrode. Nanoscale 8, 1523-1534 (2016).

8. Permyakova, A. A. et al. $\mathrm{Pt}-$ Si bifunctional surfaces for $\mathrm{CO}$ and methanol electro-oxidation. J. Phys. Chem. C 119, 8023-8031 (2015).

9. Huang, T. et al. A high-performance catalyst support for methanol oxidation with graphene and vanadium carbonitride. Nanoscale 7, 1301-1307 (2015).

10. Xie, X. et al. Site-selective trimetallic heterogeneous nanostructures for enhanced electrocatalytic performance. Adv. Mater. 27, 5573-5577 (2015).

11. Zhang, X. \& Ma, L.-X. Electrochemical fabrication of platinum nanoflakes on fulleropyrrolidine nanosheets and their enhanced electrocatalytic activity and stability for methanol oxidation reaction. J. Power Sources 286, 400-405 (2015).

12. Liu, Y. et al. Small-sized tungsten nitride particles strongly anchored on carbon nanotubes and their use as supports for pt for methanol electro-oxidation. Chem.-Eur. J. 21, 18345-18353 (2015).

13. Dai, L. et al. Morphological control and evolution of octahedral and truncated trisoctahedral Pt-Au alloy nanocrystals under microwave irradiation. Nanoscale 6, 9944-9950 (2014).

14. Zhang, P. et al. One-pot synthesis of ternary Pt-Ni-Cu nanocrystals with high catalytic performance. Chem. Mater. 27, 6402-6410 (2015).

15. Sun, X. et al. Controlling core/shell Au/FePt nanoparticle electrocatalysis via changing the core size and shell thickness. Nanoscale 8, 2626-2631 (2016).

16. Qi, J., Benipal, N., Liang, C. \& Li, W. PdAg/CNT catalyzed alcohol oxidation reaction for high-performance anion exchange membrane direct alcohol fuel cell (alcohol = methanol, ethanol, ethylene glycol and glycerol). Appl. Catal. B- Envir. 199, 494-503 (2016).

17. Guo, S. \& Wang, E. Noble metal nanomaterials: Controllable synthesis and application in fuel cells and analytical sensors. Nano Today 6, 240-264 (2011).

18. Xia, B. Y., Wu, H. B., Wang, X. \& Lou, X. W. Highly concave platinum nanoframes with high-index facets and enhanced electrocatalytic properties. Angew. Chem. Int. Ed. 52, 12337-12340 (2013).

19. He, W. et al. Pt-guided formation of Pt-Ag alloy nanoislands on Au nanorods and improved methanol electro-oxidation. J. Phys. Chem. C 113, 10505-10510 (2009).

20. Fu, S., Zhu, C., Du, D. \& Lin, Y. Enhanced electrocatalytic activities of PtCuCoNi three-dimensional nanoporous quaternary alloys for oxygen reduction and methanol oxidation reactions. ACS Appl. Mater. Inter. 8, (6110-6116 (2016).

21. Sun, J. et al. General synthesis of binary PtM and ternary $\mathrm{PtM}_{1} \mathrm{M}_{2}$ alloy nanoparticles on graphene as advanced electrocatalysts for methanol oxidation. J. Phys. Chem. A 3, 15882-15888 (2015).

22. Sun, X. et al. Core/shell Au/CuPt nanoparticles and their dual electrocatalysis for both reduction and oxidation reactions. J. Am. Chem. Soc. 136, 5745-5749 (2014).

23. Mao, J. et al. Seed-mediated synthesis of hexameric octahedral PtPdCu nanocrystals with high electrocatalytic performance. Chem. Commun. 51, 15406-15409 (2015).

24. Melvin, A. A. et al. Electrocatalyst on insulating support? Hollow silica spheres loaded with pt nanoparticles for methanol oxidation. ACS Appl. Mater. Inter. 7, 6590-6595 (2015).

25. Engelbrekt, C. et al. Atomically thin Pt shells on Au nanoparticle cores: facile synthesis and efficient synergetic catalysis. J. Phys. Chem. A 4, 3278-3286 (2016).

26. Wan, J. et al. Pt-Ni alloy nanoparticles as superior counter electrodes for dye-sensitized solar cells: experimental and theoretical understanding. Adv. Mater. 26, 8101-8106 (2014).

27. Yin, H. et al. Ultrathin platinum nanowires grown on single-layered nickel hydroxide with high hydrogen evolution activity. Nat. Commun. 6, 6430 (2015).

28. Hsu, Y.-H. et al. Au-decorated $\mathrm{GaOOH}$ nanorods enhanced the performance of direct methanol fuel cells under light illumination. Appl. Catal. B- Envir. 185, 133-140 (2016).

29. Zhang, Z. et al. One-pot synthesis of highly anisotropic five-fold-twinned PtCu nanoframes used as a bifunctional electrocatalyst for oxygen reduction and methanol oxidation. Adv. Mater. 28, 8712-8717 (2016).

30. Liao, Y. et al. Composition-tunable PtCu alloy nanowires and electrocatalytic synergy for methanol oxidation reaction. J. Phys. Chem. C 120, 10476-10484 (2016).

31. Hu, Y. et al. Bimetallic Pt-Au nanocatalysts electrochemically deposited on graphene and their electrocatalytic characteristics towards oxygen reduction and methanol oxidation. Phys. Chem. Chem. Phys. 13, 4083-4094 (2011).

32. Eid, K. et al. One-step synthesis of porous bimetallic PtCu nanocrystals with high electrocatalytic activity for methanol oxidation reaction. Nanoscale 7, 16860-16866 (2015).

33. Xu, X. et al. Synthesis of Pt-Ni alloy nanocrystals with high-index facets and enhanced electrocatalytic properties. Angew. Chem. Int. Ed. 53, 12522-12527 (2014).

34. Yin, Z. et al. Supported Pd-Cu bimetallic nanoparticles that have high activity for the electrochemical oxidation of methanol. Chem.-Eur. J. 18, 4887-4893 (2012).

35. You, H., Yang, S., Ding, B. \& Yang, H. Synthesis of colloidal metal and metal alloy nanoparticles for electrochemical energy applications. Chem. Soc. Rev. 42, 2880-2904 (2013).

36. Lu, C. et al. Gold-platinum bimetallic nanotubes templated from tellurium nanowires as efficient electrocatalysts for methanol oxidation reaction. J. Power Sources 296, 102-108 (2015).

37. Hong, W., Wang, J. \& Wang, E. Scalable synthesis of Cu-based ultrathin nanowire networks and their electrocatalytic properties. Nanoscale 8, 4927-4932 (2016).

38. Xia, B. Y. et al. One-pot synthesis of Pt-Co alloy nanowire assemblies with tunable composition and enhanced electrocatalytic propertie. Angew. Chem. Int. Ed. 54, 3797-3801 (2015).

39. Bai, J., Fang, C.-L., Liu, Z.-H. \& Chen, Y. A one-pot gold seed-assisted synthesis of gold/platinum wire nanoassemblies and their enhanced electrocatalytic activity for the oxidation of oxalic acid. Nanoscale 8, 2875-2880 (2016).

40. Qiu, X. et al. Template-engaged synthesis of hollow porous platinum-palladium alloy nanospheres for efficient methanol electrooxidation. J. Power Sources 302, 195-201 (2016).

41. Gu, J., Zhang, Y.-W. \& Tao, F. Shape control of bimetallic nanocatalysts through well-designed colloidal chemistry approaches. Chem. Soc. Rev. 41, 8050-8065 (2012).

42. Li, Y. et al. Synthesis of core-shell Au-Pt nanodendrites with high catalytic performance via overgrowth of platinum on in situ gold nanoparticles. J. Phys. Chem. A 3, 368-376 (2015).

43. Wang, S., Yang, G. \& Yang, S. Pt-frame@Ni quasi core-shell concave octahedral $\mathrm{PtNi}_{3}$ bimetallic nanocrystals for electrocatalytic methanol oxidation and hydrogen evolution. J. Phys. Chem. C 119, 27938-27945 (2015).

44. Yuan, W. et al. Controllably self-assembled graphene-supported Au@Pt bimetallic nanodendrites as superior electrocatalysts for methanol oxidation in direct methanol fuel cells. J. Phys. Chem. A 4, 7352-7364 (2016).

45. Banerjee, I., Kumaran, V. \& Santhanam, V. Synthesis and characterization of Au@Pt nanoparticles with ultrathin platinum overlayers. J. Phys. Chem. C 119, 5982-5987 (2015). 
46. Yan, S. et al. Application of carbon supported Ptcore-Aaushell nanoparticles in methanol electrooxidation. J. Phys. Chem. C 118, 29845-29853 (2014).

47. Mikkelsen, K. et al. Block copolymer templated synthesis of core-shell PtAu bimetallic nanocatalysts for the methanol oxidation reaction. Chem. Mater. 26, 6928-6940 (2014).

48. Qiu, H. J. et al. Core-shell-structured nanoporous $\mathrm{PtCu}$ with high $\mathrm{Cu}$ content and enhanced catalytic performance. J. Phys. Chem. A 3, 7939-7944 (2015).

49. Su, S. et al. Uniform Au@Pt core-shell nanodendrites supported on molybdenum disulfide nanosheets for the methanol oxidation reaction. Nanoscale 8, 602-608 (2016).

50. Chen, L.-X. et al. Oligonucleotide-assisted successive coreduction synthesis of dendritic platinum-gold core-shell alloy nanocrystals with improved electrocatalytic performance for methanol oxidation. J. Power Sources 302, 140-145 (2016).

51. Shi, J. et al. Efficient metal-free organic sensitizers containing tetraphenylethylene moieties in the donor part for dye-sensitized solar cells. Eur. J. Org. Chem. 2012, 5248-5255 (2012).

52. Zhang, Y. et al. Concave Pd-Pt core-shell nanocrystals with ultrathin pt shell feature and enhanced catalytic performance. Small 12, 706-712 (2016)

53. Kim, Y., Lee, Y. W., Kim, M. \& Han, S. W. One-pot synthesis and electrocatalytic properties of Pd@Pt core-shell nanocrystals with tailored morphologies. Chem.-Eur. J. 20, 7901-7905 (2014).

54. Ishida, T. \& Haruta, M. Gold catalysts: Towards sustainable chemistry. Angew. Chem. Int. Ed. 46, 7154-7156 (2007).

55. Bi, Q.-Y. et al. Efficient subnanometric gold-catalyzed hydrogen generation via formic acid decomposition under ambient conditions. J. Am. Chem. Soc. 134, 8926-8933 (2012).

56. Liu, X. et al. Gold-catalyzed direct hydrogenative coupling of nitroarenes to synthesize aromatic azo compounds. Angew. Chem. Int. Ed. 53, 7624-7628 (2014)

57. Su, F. et al. Dendritic $\mathrm{Au} / \mathrm{TiO}_{2}$ nanorod arrays for visible-light driven photoelectrochemical water splitting. Nanoscale 5, 9001-9009 (2013).

58. Cameron, D., Holliday, R. \& Thompson, D. Gold's future role in fuel cell systems. J. Power Sources 118, 298-303 (2003).

59. Rolison, D. R. Catalytic nanoarchitectures-the importance of nothing and the unimportance of periodicity. Science 299, 1698-1701 (2003).

60. Jaramillo, T. F., Baeck, S.-H., Cuenya, B. R. \& McFarland, E. W. Catalytic activity of supported au nanoparticles deposited from block copolymer micelles. J. Am. Chem. Soc. 125, 7148-7149 (2003).

61. You, H., Zhang, F., Liu, Z. \& Fang, J. Free-standing Pt-Au hollow nanourchins with enhanced activity and stability for catalytic methanol oxidation. ACS Catal. 4, 2829-2835 (2014).

62. Zhao, Z. L., Zhang, L. Y., Bao, S. J. \& Li, C. M. One-pot synthesis of small and uniform Au@PtCu core-alloy shell nanoparticles as an efficient electrocatalyst for direct methanol fuel cells. Appl. Catal. B- Envir. 174-175, 361-366 (2015)

63. Zhao, D. \& Xu, B.-Q. Enhancement of Pt utilization in electrocatalysts by using gold nanoparticles. Angew. Chem. Int. Ed. 45, 4955-4959 (2006).

64. Luo, J. et al. Activity-composition correlation of AuPt alloy nanoparticle catalysts in electrocatalytic reduction of oxygen. Electrochem. Commun. 8, 581-587 (2006).

65. Luo, J. et al. Characterization of carbon-supported AuPt nanoparticles for electrocatalytic methanol oxidation reaction. Langmuir 22, 2892-2898 (2006)

66. Luo, J. et al. Electrocatalytic oxidation of methanol: carbon-supported gold-platinum nanoparticle catalysts prepared by two-phase protocol. Catal. Today 99, 291-297 (2005).

67. Luo, M. et al. Facile removal of polyvinylpyrrolidone (PVP) adsorbates from Pt alloy nanoparticles. J. Phys. Chem. A 3, 2770-2775 (2015).

68. Jiang, B. et al. Multimetallicmesoporous spheres through surfactant-directed synthesis. Advanced Science 2, n/a-n/a (2015).

69. Tsung, C.-K. et al. Sub-10 nm platinum nanocrystals with size and shape control: Catalytic study for ethylene and pyrrole hydrogenation. J. Am. Chem. Soc. 131, 5816-5822 (2009).

70. Senapati, S., Das, S. P. \& Patnaik, A. K. Kinetics and Mechanism of Oxidation of L-Ascorbic Acid by Pt(IV)(aq) in Aqueous Hydrochloric Acid Medium. Adv. Phys. Chem. 2012, 143734 (2012)

71. Xu, C. et al. Hierarchical nanoporous PtFe alloy with multimodal size distributions and its catalytic performance toward methanol electrooxidation. Langmuir 28, 1886-1892 (2012).

72. Franceschini, E. A. et al. Mesoporous Pt and Pt/Ru alloy electrocatalysts for methanol oxidation. J. Power Sources 196, 1723-1729 (2011).

73. Zhao, D. \& Xu, B.-Q. Enhancement of Pt utilization in electrocatalysts by using gold nanoparticles. Angew. Chem. 118, 5077-5081 (2006).

74. Suntivich, J. et al. Surface Composition Tuning of Au-Pt Bimetallic Nanoparticles for Enhanced Carbon Monoxide and Methanol Electro-oxidation. J. Am. Chem. Soc. 135, 7985-7991 (2013).

75. Zhang, Z., Wang, Y. \& Wang, X. Nanoporous bimetallic Pt-Au alloy nanocomposites with superior catalytic activity towards electrooxidation of methanol and formic acid. Nanoscale 3, 1663-1674 (2011).

76. Ge, X., Wang, R., Liu, P. \& Ding, Y. Platinum-decorated nanoporous gold leaf for methanol electrooxidation. Chem. Mater. 19, $5827-5829$ (2007).

77. Wang, D.-Y. et al. Simple replacement reaction for the preparation of ternary Fe1-xPtRux nanocrystals with superior catalytic activity in methanol oxidation reaction. J. Am. Chem. Soc. 134, 10011-10020 (2012).

78. Lin, Z.-H., Shih, Z.-Y., Tsai, H.-Y. \& Chang, H.-T. Gold/Platinum nanosponges for electrocatalytic oxidation of methanol. Green Chem. 13, 1029-1035 (2011).

\section{Acknowledgements}

This work was supported by the National Natural Science Foundation of China (Project Code, 21373144) and the International Collaboration program granted by the Chinese Ministry of Science and Technology (2016YFE0129800). This is also a project supported by the 111 Project, the Natural Science Foundation of Jiangsu Province (Project Code, BK20150007 and BK20151228), the Natural Science Foundation in High Education of Jiangsu Province (16KJB430024), and by the Collaborative Innovation Center of Suzhou Nano Science and Technology and the Priority Academic Program Development of Jiangsu Higher Education Institutions (PAPD).

\section{Author Contributions}

C.T. performed the catalyst preparation and performance tests. Y.S. analyzed the data and co-wrote the paper. J.Z., D.W., Z.L., H.Z. and J.G. collected and analyzed the data. L.J. and L.J. planned and supervised the project. All authors discussed and commented on the manuscript.

Additional Information

Supplementary information accompanies this paper at doi:10.1038/s41598-017-06639-5 
Competing Interests: The authors declare that they have no competing interests.

Publisher's note: Springer Nature remains neutral with regard to jurisdictional claims in published maps and institutional affiliations.

(c) (i) Open Access This article is licensed under a Creative Commons Attribution 4.0 International (c) License, which permits use, sharing, adaptation, distribution and reproduction in any medium or format, as long as you give appropriate credit to the original author(s) and the source, provide a link to the Creative Commons license, and indicate if changes were made. The images or other third party material in this article are included in the article's Creative Commons license, unless indicated otherwise in a credit line to the material. If material is not included in the article's Creative Commons license and your intended use is not permitted by statutory regulation or exceeds the permitted use, you will need to obtain permission directly from the copyright holder. To view a copy of this license, visit http://creativecommons.org/licenses/by/4.0/.

(c) The Author(s) 2017 